\title{
Preparation of Medicated Polylactide Micropieces by Means of Ultrasonic Technology
}

\author{
Cristian Olmo ${ }^{1}$, Lourdes Franco $1,2, * \mathbb{C}$, Luis J. del Valle ${ }^{1,2}$ and Jordi Puiggalí ${ }^{1,2, *}$ \\ 1 Departament d'Enginyeria Química, Universitat Politècnica de Catalunya, Escola d'Enginyeria de Barcelona \\ Est-EEBE, 08019 Barcelonax, Spain; olmocristian@gmail.com (C.O.); luis.javier.del.valle@upc.edu (L.J.d.V.) \\ 2 Barcelona Research Center for Multiscale Science and Engineering, Universitat Politècnica de Catalunya, \\ Escola d'Enginyeria de Barcelona Est-EEBE, 08019 Barcelona, Spain \\ * Correspondence: Lourdes.Franco@upc.edu (L.F.); Jordi.Puiggali@upc.edu (J.P.); \\ Tel.: +34-93-401-1870 (L.F.); +34-93-401-5649 (J.P.)
}

Received: 8 May 2019; Accepted: 6 June 2019; Published: 9 June 2019

Featured Application: Drug loaded micropieces can be easily processed by means of a new ultrasound technology. This can minimize the degradation observed when other more conventional processes are applied.

\begin{abstract}
A technology based on the application of ultrasound as an energy source was applied to get polylactide (PLA) micropieces with minimum degradation and processing time. This requirement could be even shorter than $1.5 \mathrm{~s}$. The ultrasound technology was also demonstrated to be efficient for the incorporation of drugs with a pharmacological activity. Thus, the loading of two representative bactericide agents (i.e., triclosan (TCS), and chlorhexidine (CHX)), having differentiated chemical properties was evaluated. Typical physicochemical characterization included mechanical and thermal properties together with the evaluation of molecular degradation during processing for both unloaded and loaded specimens. Results pointed out that the thermally stable TCS could be loaded into the specimens without any problem, but cautions should be taken into account for CHX. Nevertheless, degradation could in this case be avoided when the drug load was lower than $3 \mathrm{wt}-\%$, a result that contrasts with the significant decomposition attained by using conventional melting processes, which required long processing times at high temperatures. Morphologic analyses of loaded specimens did not reveal significant defects, while spectroscopic analyses showed that a good dispersion of drugs inside pieces could be attained. Drugs were slowly released from micropieces with a rate that was dependent on their hydrophilic character. Thus, release in a phosphate buffered saline (PBS)-ethanol medium (70\% of PBS) followed a first order kinetics with constants of $0.0356 \mathrm{~h}^{-1}$ and $0.027 \mathrm{~h}^{-1}$ for CHX and TCS, respectively. A clear bactericide effect against both Gram-positive and Gram-negative bacteria was achieved at the beginning of exposure to the corresponding culture media, while a bacteriostatic effect was interestingly still detected after long exposure times. In fact, bacterial growth could be reduced to near $20 \%$ when micropieces were loaded with only $3 \mathrm{wt}-\%$ of any of the selected CHX and TCS drugs.
\end{abstract}

Keywords: ultrasound micromolding; micropieces; polylactide; antibacterial activity; biomedical properties; drug release; triclosan; chlorhexidine

\section{Introduction}

Nowadays, the use of pieces with reduced dimensions has increased in several commercial sectors, especially in electronic and medicine fields. Some examples of these devices are microchips, nanoneedles or pumps for microfluidics [1-3]. The wide range of applications and the high resolution 
required for the final performance have enhanced the interest towards the use of polymers for these purposes due to their versatility. However, the technology to produce them in a large scale is still under development.

There are some techniques to mold polymers in a microsize scale as hot embossing, thermoforming or microinjection $[4,5]$. The former ones are mainly employed in a laboratory scale, limiting their applicability for a large-scale processing. On the other hand, microinjection equipment has been introduced in the market and is widely used to get microsamples in a commercial way. However, production cost is high due to the procedure itself and consequently microinjection application is somehow restricted. Microinjection equipment is a simple adaptation of conventional injection equipment where a microsized mold is connected by an adapted pipe. For this reason, the dosage of the material is really poor, the feeding is excessive, and the amount of non-useful material is huge, in some cases even more than $90 \%$. Moreover, the produced molten material is more than required leading to an elevated energy cost and a large cycle time process [6,7].

In the search of new technologies to obtain small pieces, some studies come up with the development of processing techniques based on the use of ultrasound as a heating source. This technique has been applied for over 40 years as standard assembly procedure [8] where ultrasonic welding is based on a local melting in a thermoplastic surface. The polymer heating is generated from inside to outside the material as a result of internal polymer chain friction. This heating technique is highly efficient and accurate; moreover, ultrasound vibration increases the motion of molecular chain dropping the polymer viscosity and facilitating the molten polymer flow [9]. Some prototypes have been launched based on this heating concept combined with direct injection to plasticize material [10]. This process also offers a highly efficient dosage system, delivering just the amount of material required. The potential applications of this methodology are clear, being up to now different studies conducted to improve knowledge about the effect of ultrasound in the melting process of some commodities, such as polyethylene or polystyrene [11,12]. In addition, this technology is being considered for biodegradable polymers with biomedical applications, such as polylactide (PLA) [7].

PLA is an aliphatic polyester (i.e., a poly $\alpha$-hydroxyacid), which can be obtained from renewal sources, such as sugar cane and starch. PLA is a biocompatible polymer which can be biodegraded into lactic acid, has low immunologic toxicity and good mechanical properties. Furthermore, PLA has been approved by the food drug administration (FDA) for clinical assays [13] and therefore its use in the biomedical field is widely extended. Specifically, PLA is employed in medical implants such as screws, pins or meshes [14,15], bioabsorbable sutures [16,17], tissue engineering applications [18-20] and drug-delivery systems [21,22].

One of the potential applications of ultrasonic micromolding is the possibility to incorporate drugs inside the polymer matrix and perform the molding process in a single step. Considering the prolonged cycle time and the mechanical stress suffered by the polymer, the conventional injection process is not suitable for the direct loading of thermally unstable drugs. In most cases, drugs degrade and become biologically inactive. On the contrary, ultrasonic micromolding can reduce the time at which the sample should be exposed to the power source (e.g., 1-2 s in our case as will then be explained). Hence, it seems a proper procedure to produce drug-delivery pieces with its final shape in a single step [23]. A promising application could be mass production of medical screws or other implants loaded with antibacterial drugs. In this way, drug effectiveness would be improved by reducing the drug amount, targeting the effect against possible infections and facilitating the implant incorporation [24]. One of the broadest biomedical applications of biodegradable materials is their use as temporary supports. In these cases, the rate of biodegradation must not exceed the rate of cell colonization for an effective replacement of the material by the regenerated cell tissue. Materials loaded with drugs do not necessarily have to release the drug according to its degradation (e.g., bulk or surface erosion). Depending on the application, a rapid release may be required (e.g., when a microbiological colonization of the material should be avoided), but, in addition, a sustained and prolonged release 
may also be required. Therefore, biodegradation and the release of the drug should not necessarily occur in a synchronized manner.

The main goal of this work is centered on the evaluation of the possibility of getting PLA microspecimens with a biomedical added value. The aim is to incorporate antibacterial drugs in a PLA matrix by ultrasonic micromolding, study the effect of representative drugs (Scheme 1) in the final piece, evaluate the release kinetics of the loaded drugs, and determine if the ultrasonic heating affects the antibacterial function.

Triclosan (TCS) and chlorhexidine (CHX) are two well-known bactericide agents with differentiated size (i.e., molecular sizes of 290 and $505 \mathrm{~g} / \mathrm{mol}$ for TCS and CHX, respectively), physical properties (e.g., solubility) and functional groups (i.e., hydroxyl for TCS and biguanidine for CHX) (Scheme 1). These different characteristics have prompted us to select them as representative examples.
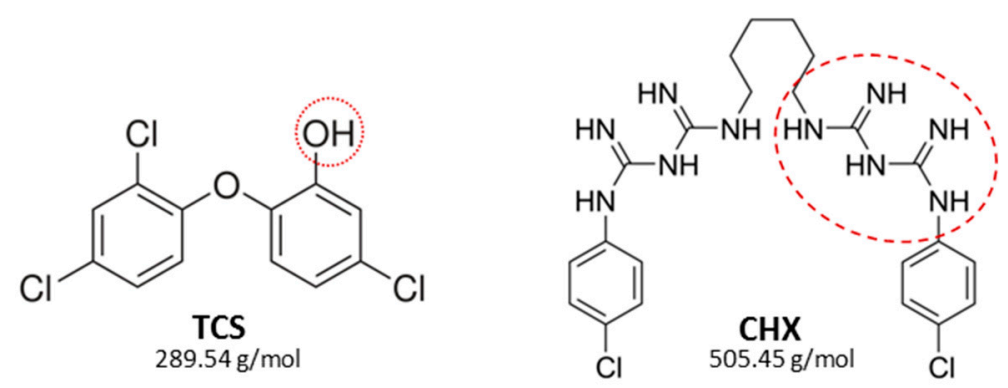

Scheme 1. Chemical formulas of the selected antibacterial drugs. Dashed red circles point out distinctive functional.

\section{Materials and Methods}

\subsection{Materials}

The employed powdered PLA was a commercial grade Ecorene ${ }^{\circledR}$ NW30 (NatureWorks, Naarden, The Netherlands), characterized by a high crystallinity $(35 \%)$ and low molecular weight $\left(M_{n}\right.$ of $43,000 \mathrm{~g} / \mathrm{mol}$ ). The chosen TCS and CHX were supplied by Sigma-Aldrich ${ }^{\circledR}$ (Madrid, Spain).

\subsection{Micromolding Equipment and Sample Preparation}

A first-generation prototype Ultrasound Molding Machine (Sonorus ${ }^{\circledR}$, Ultrasion S.L., Barcelona, Spain) was employed. The apparatus, shown in Figure 1, was equipped with a digital ultrasound generator from Mecasonic (1000 W-30 kHz, Barcelona, Spain), a controller (3010 DG digital system, Mecasonic, Barcelona, Spain), a focused piezoelectric transducer (Mecasonic), an acoustic unit (booster and sonotrode) designed by Mecasonic and operating in longitudinal vibration mode, an electric servomotor control (Berneker and Rainer) with software from Ultrasion S.L. (Barcelona, Spain) and a thermally controlled mold. This mold was designed to prepare eight test specimens of dimensions $1.5 \mathrm{~cm} \times 0.1 \mathrm{~cm} \times 0.1 \mathrm{~cm}$ and equipped with and ejection system to easily release the molded sample. The sonotrode transfers vibration energy to the material and provides the pressure required to transfer it into the mold. The amount of vibration energy generated depends on the amplitude level.

For the sample preparation, $380 \mathrm{mg}$ of powered PLA (or its mixture with the selected drug) were loaded on the feeding point. In the first stage, the sonotrode compacted the powdered sample and then the transducer converted the electric energy to a vibration movement regulated by the booster, according to the wave amplitude previously set up. This cycled vibration was able to melt and mold the polymer, and facilitated its flow. Once the vibration was stopped, the mold was cold down at constant pressure and the specimen was released with the ejection system. The full process is summarized in Figure 2. 


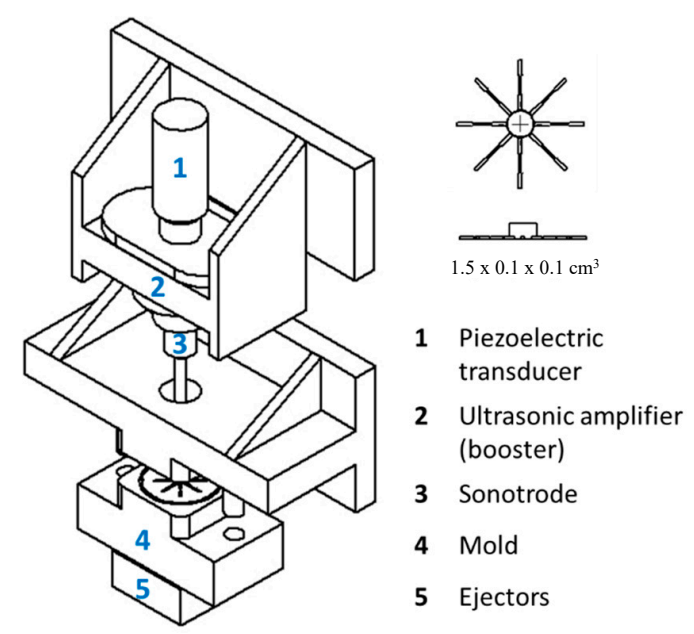

Figure 1. Diagram of the main parts of the micro-molding equipment.

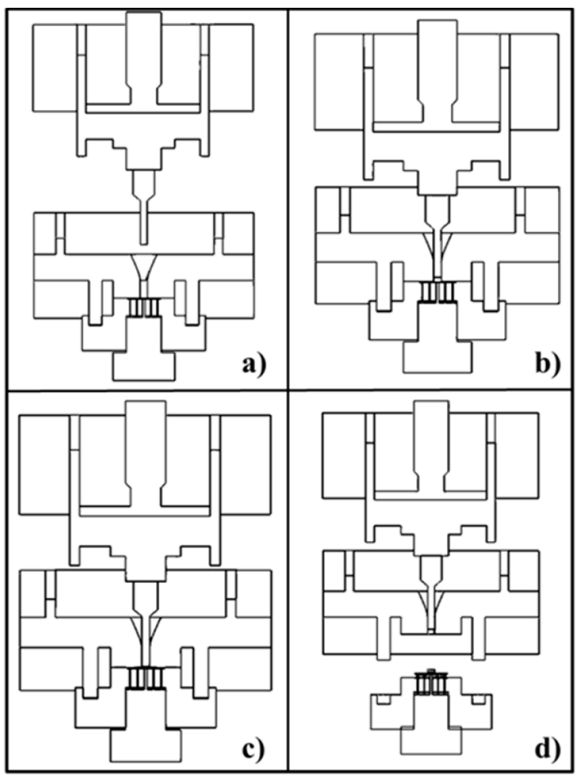

Figure 2. Schematic representation of the molding process: (a) feed position; (b) compression of sample; (c) ultrasound turn on and molding; and (d) ejection.

\subsection{Specimen Characterization}

Molecular weight was estimated by size exclusion chromatography (GPC) using a liquid chromatograph (Shimadzu, model LC-8A, Tokyo, Japan) equipped with an Empower computer program (Waters, company, city, country, year). The polymer was dissolved and eluted in 1,1,1,3,3,3-hexafluoroisopropanol (HFIP) containing $\mathrm{CF}_{3} \mathrm{COONa}(0.05 \mathrm{M})$. The flow rate was $1 \mathrm{~mL} / \mathrm{min}$, the injected volume $20 \mu \mathrm{L}$, and the sample concentration $2 \mathrm{mg} / \mathrm{mL}$. A PL HFIP gel column ((Polymer Lab, Agilent Technologies Deutschland $\mathrm{GmbH}$, Böblingen, Germany)) and a refractive index detector (Shimadzu RID-10A) were employed. The number and weight average molecular weights were determined using polymethylmethacrylate standards.

Infrared absorption spectra were recorded, at a resolution of $4 \mathrm{~cm}^{-1}$, with a Fourier transform FTIR 4100 Jasco spectrometer (Tokyo, Japan). A Specac MKII Golden Gate Single Reflection Diamond ATR system (Specac, Kent, England) which can be used up to $200^{\circ} \mathrm{C}$, and a high stability 4000 series controller were also employed.

A Focused Ion Beam Zeiss Neon40 microscope (Zeiss, Oberkochen, Germany) operating at $5 \mathrm{kV}$ was used to obtain SEM micrographs of micromolded specimens. Samples were mounted on a 
double-side adhesive carbon disc and sputter-coated with a thin layer of carbon by using a Mitec K950 Sputter Coater (Quorum Technologies Ltd., Ashford, UK).

Tensile deformation tests were performed using the Universal Testing Machine Zwick Z 2.5 (Barcelona, Spain) equipped with a cell charge of $100 \mathrm{~N}$ and testXpert 8.1 software (Zwick, Ulm, Germany). Gauge length was $5 \mathrm{~mm}$ and test crosshead speed was $1 \mathrm{~mm} / \mathrm{min}$, fifteen specimens $\left(1.5 \times 0.1 \times 0.1 \mathrm{~cm}^{3}\right)$ were tested for each processing condition. The width of each one was accurately measured with width measurement equipment Uno-Check Fe (Neurtek Instruments, Eibar, Spain).

\subsection{Calorimetric Properties}

Calorimetric data were recorded by differential scanning calorimetry (DSC) using a TA instrument (New Castle, DE, USA) Q100 series equipped with a refrigerated cooling system operating from -90 to $550{ }^{\circ} \mathrm{C}$. Experiments were performed under a flow of dry nitrogen with a sample of ca. $5 \mathrm{mg}$. The instrument was calibrated for temperature and heat of fusion using an indium standard. Tzero technology required two calibrations, with empty pans and sapphire discs.

Thermal characterization of polymers was carried out following a protocol consisting of three runs: a heating run of the as-molded sample, a cooling run after keeping the sample in the melt for $3 \mathrm{~min}$ and a second heating run of the nonisothermally crystallized sample. All scans were done at $10^{\circ} \mathrm{C} / \mathrm{min}$.

Thermogravimetric analysis (TGA) and differential thermogravimetric analysis (DTGA) data were acquired with a Q50 thermogravimetric analyzer of TA Instruments (New Castle, DE, USA) under a flow of dry nitrogen with approximately $5 \mathrm{mg}$ samples and at a heating rate of $20^{\circ} \mathrm{C} / \mathrm{min}$.

\subsection{Release and Quantification}

Quantification analysis of the loaded drugs was done by means of a spectrophotometer Shimadzu UV-3600. Calibration curves were done with pure drugs dissolved in ethanol and measuring absorbance at $292 \mathrm{~nm}$ and $259 \mathrm{~nm}$ for TCS and CHX, respectively.

Studied specimens were cut in three different sections. These as well as the sprue were dissolved in $100 \mu \mathrm{L}$ of chloroform and then the drug was extracted with $900 \mu \mathrm{L}$ of ethanol. For each part, the percentage of drug was calculated by the use of the calibration curves previously done, and each measurement was performed in triplicate.

Encapsulation efficiency (EE) and drug loading (DL) were determined by Equations (1) and (2), respectively:

$$
\mathrm{EE}(\%)=100 \times \text { Weight of drug found in the specimen/Weight of added drug, }
$$

DL $(\%)=100 \times$ Weight of drug found in the specimen/Weight of the unloaded specimen.

Release experiments were carried out in triplicate with specimens exposed in $10 \mathrm{~mL}$ of the selected release media, keeping the specimen under a moderate stirring $(80 \mathrm{rpm})$ and constant temperature of $37^{\circ} \mathrm{C}$ for one week. In this period, aliquots of $1 \mathrm{~mL}$ were taken out of the media and analyzed by $\mathrm{UV}$ spectroscopy to quantify the amount of drug released. After each extraction, the media were renewed with fresh solutions.

\subsection{Inhibition of Bacterial Growth}

Escherichia coli (E. coli) and Staphylococcus Epidemidis (S. epidermidis) were selected to evaluate the antibacterial activity of drugs loaded in PLA. The bacteria were previously grown aerobically to exponential phase in lysogeny broth (LB) (Lennox) (tryptone 10 g; yeast extract $5 \mathrm{~g}, \mathrm{NaCl} 5 \mathrm{~g}, \mathrm{pH}$ 7.2). Growth experiments were performed placing three specimens $(1.5 \mathrm{~cm} \times 0.5 \mathrm{~cm} \times 0.5 \mathrm{~cm})$ of each sample in tubes of $15 \mathrm{~mL}$; neat PLA, PLA-CHX $3 \mathrm{wt}-\%$ and PLA-TCS $3 \mathrm{wt}-\%$. After this, $2 \mathrm{~mL}$ of broth culture containing $1 \times 10^{3}$ colony forming units (CFU) were seeded in each sample-containing tube. The cultures were incubated at $37^{\circ} \mathrm{C}$ and agitated at $80 \mathrm{rpm}$. Aliquots of $100 \mu \mathrm{L}$ were taken at 
predefined time intervals for absorbance measurement at $650 \mathrm{~nm}$ in a reader plate. Thus, turbidity was directly related to bacterial growth. The maximum bacterial growth (control) was that determined in broth culture with the unloaded PLA specimen and it was used to calculate the relative growth of the bacteria in the presence of the drug loaded samples. Values were averaged considering three replicas. Agar diffusion tests were performed in Petri dishes of $90 \mathrm{~mm}$ and seeded separately with $1.5 \times 10^{8} \mathrm{CFU} / \mathrm{mL}$ of each bacterium. Four samples were placed on each Petri plate; neat PLA (as negative control) and samples loaded with $1.5 \mathrm{wt}-\%, 3 \mathrm{wt}-\%$ and $6 \mathrm{wt}-\%$ of each drug. Inhibition halo images were taken after incubation of samples with bacteria for $24 \mathrm{~h}$ at $37^{\circ} \mathrm{C}$.

\section{Results}

\subsection{Set Up of Molding Conditions}

As mentioned before, this new processing technique is based on the use of ultrasound as a heating source. Hence, molding parameters such as ultrasound intensity or wave amplitude do not have not a clear correlation with physical characteristics of processed specimens compared with the well-established knowledge concerning conventional micromolding machines. In this case, polymer properties, such as melting point or flow index, are easily related to heating and pumping intensity, whereas ultrasound micromolding needs further research to arrive to a similar know how [7]. Furthermore, new insights concerning ultrasound induced micromolding should be mentioned, which indicated the influence of additional effects such as acoustic streaming [25] and acoustic radiation forces [26].

Therefore, an empirical study has been done to determine correct molding conditions for neat PLA before processing with the different drug loaded samples. Specifically, assays have been carried out to cover the following points:

1. To find appropriate energy and molding force values to fill the whole mold. These were based with previous works carried out with neat PLA [7]. Through a visual inspection (the eight test specimens were fully molded or not), it could be concluded that working with an amplitude lower than $24 \mu \mathrm{m}$ was not enough to reach an appropriate flow of PLA (Table 1). In reference to the molding force, a value above $300 \mathrm{~N}$ was needed to get the eight specimens full. However, caution should be taken into account since forces around 500-600 N were not stable and, in some cases, the sonotrode was overloaded (i.e., it cannot vibrate) due to a high PLA compaction.

2. To compare the molecular weight of molded sample with the original polymer. One of the main issues of this process is the possibility of polymer degradation (i.e., rupture of the polymer chain in oligomers) that could compromise the final physical properties of the molded specimen [9]. GPC measurements of samples processed under different conditions are summarized in Table 1. PLA seems to be very flexible with the molding condition in comparison with other polymers [13]. Molecular weight variation was not detected for the applied range of force. However, the increase of the molding time caused a significant degradation. It can be assumed that a molding time equal or lower than $1.2 \mathrm{~s}$ may cause a minimum degradation of PLA.

3. To confirm that chemical structure of the polymer molded keeps the FTIR spectrum of a PLA specimen molded unaltered at the optimized condition of $300 \mathrm{~N} 1.2 \mathrm{~s} 24 \mu \mathrm{m}$, according to the filling efficiency and GPC assay, were compared with the spectrum of commercial powdered PLA (Figure 3). It is clear that the ultrasonic source has not given rise to any significant modification of the chemical structure of the polymer. The typical bands of ester $\left(1745,1266\right.$ and $\left.1108 \mathrm{~cm}^{-1}\right)$ and methylene groups $\left(1455 \mathrm{~cm}^{-1}\right.$ and $\left.1380 \mathrm{~cm}^{-1}\right)$ remained unchanged.

4. To check by visual inspection the presence of fissures and cracks inside the processed samples, features that may affect the final mechanical properties of specimens. Figure 4 shows SEM micrographs of the processed sample under optimal parameters where significant physical defects cannot be detected. 


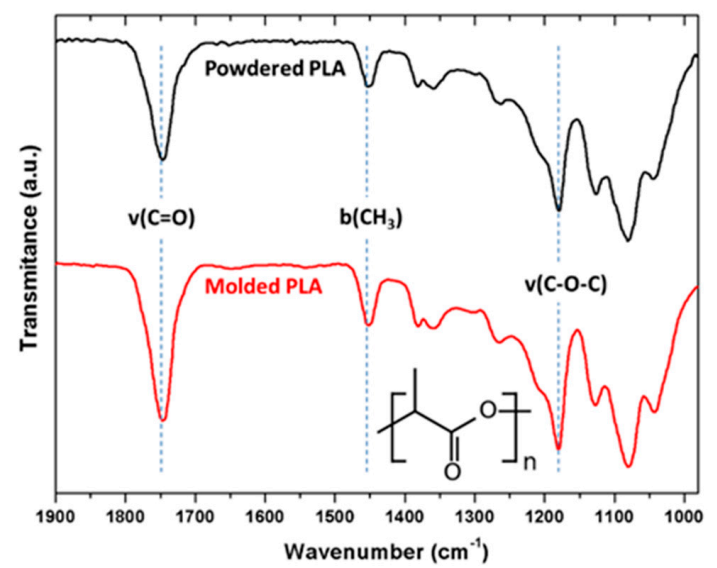

Figure 3. FTIR spectrum of polylactide (PLA) efore (black) and after (red) being molded.

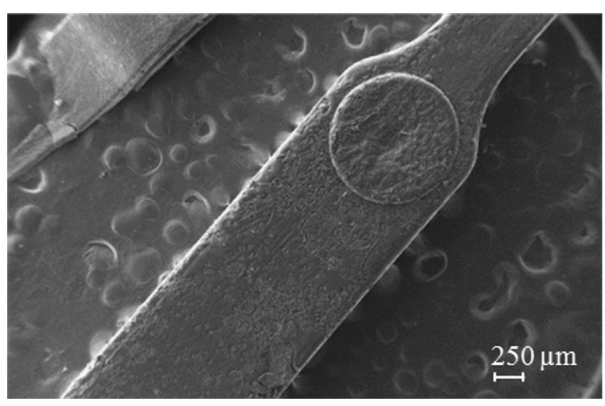

(a)

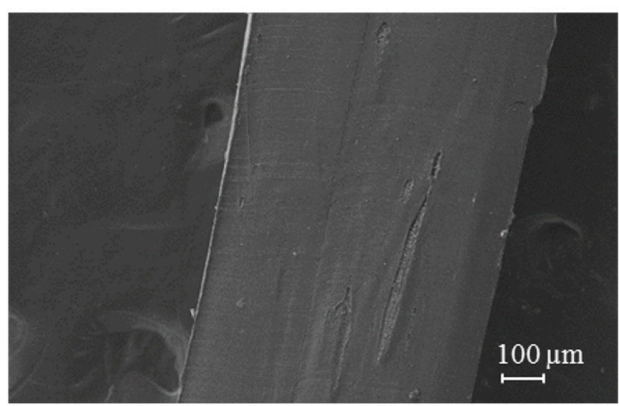

(b)

Figure 4. SEM micrographs taken at different magnifications of a PLA specimen molded at 24-300-1.2 condition.

Table 1. Molding efficiency and molecular weight of a polylactide (PLA) sample molded under several conditions ${ }^{\mathrm{a}}$.

\begin{tabular}{ccccc}
\hline Molding $^{\mathbf{b}}$ & Efficiency (\%) $^{\mathbf{c}}$ & $\boldsymbol{M}_{\boldsymbol{n}} \mathbf{( \mathrm { g } / \mathbf { m o l } )}$ & $\boldsymbol{M}_{\boldsymbol{w}}(\mathrm{g} / \mathbf{m o l})$ & $\boldsymbol{M}_{\boldsymbol{w}} / \boldsymbol{M}_{\boldsymbol{n}}$ \\
\hline Raw & - & 43,000 & 69,100 & 1.64 \\
$24-200-1.5$ & 40 & 35,400 & 69,700 & 1.96 \\
$24-300-1$ & 100 & 34,500 & 68,600 & 1.98 \\
$\mathbf{2 4 - 3 0 0 - 1 . 2}$ & $\mathbf{1 0 0}$ & $\mathbf{3 8 , 8 0 0}$ & $\mathbf{7 2 , 2 0 0}$ & $\mathbf{1 . 8 8}$ \\
$24-300-3$ & 100 & 32,200 & 64,300 & 2.01 \\
$24-400-1$ & 80 & - & - & 1.89 \\
$24-400-1.5$ & 100 & 37,700 & 71,300 & 1.99 \\
$24-500-1.5$ & $-O v l-$ & 33,900 & 67,500 & - \\
\hline
\end{tabular}

a Bold characters indicate the optimized conditions and the corresponding measurements. ${ }^{\mathrm{b}}$ Micro-molding conditions: Amplitude $(\mu \mathrm{m})$, force $(\mathrm{N})$ and time $(\mathrm{s}) .{ }^{\mathrm{c}}$ Mold filling, qualitative evaluation (i.e., 8 half pieces or 4 full corresponded to $50 \%$ ). - Ovl-: Sonotrode overload.

\subsection{Characterization of PLA Specimens Loaded with Drugs}

The influence of the incorporation of different amounts of TCS and CHX on the ultrasound micromolding processing of PLA was followed by FTIR spectroscopy and GPC measurements.

Figure 5 shows that CHX can be detected in the FTIR spectra of specimens even for the lowest load. Thus, bands related to the biguanide compound appearing at $1640 \mathrm{~cm}^{-1}, 1530 \mathrm{~cm}^{-1}$ and $1490 \mathrm{~cm}^{-1}$ could be seen, even for a load of only $1 \%$-wt. The intensity of those bands gets higher with the increase of the CHX amount. On the contrary, the infrared spectrum of TCS loaded samples did not show any characteristic band associated with the drug (i.e., those appearing at 1598, 1579, 1507, 1471, 1417 and $1392 \mathrm{~cm}^{-1}$ ) and only the spectra of PLA were detected (not shown). A potential explanation is the 
lower intensity of TCS bands but also to the hydrophobic character of TCS that could improve its dispersion in the PLA hydrophobic matrix. On the contrary, the high hydrophilicity of CHX may favor its disposition onto the PLA specimen surface, its detection by ATR measurements being increased.

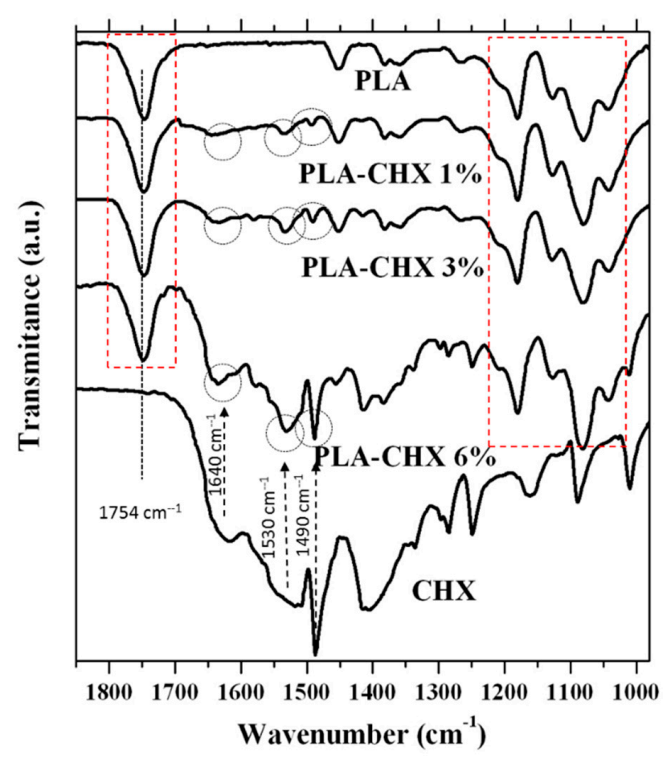

Figure 5. Infrared absorption spectra of PLA, PLA samples loaded with different amounts of chlorhexidine (CHX) and pure CHX. Dashed red boxes indicated bands associated with PLA.

GPC curves were recorded for specimens loaded with different percentages of TCS and CHX and processed under the conditions optimized for the PLA matrix ( $24 \mu \mathrm{m}-300 \mathrm{~N}-1.2 \mathrm{~s})$. In this way, the effect of the type of drug and percentage can be determined, it being possible in a subsequent work to change the ultrasound parameters (i.e., amplitude, force and time) in order to improve processing.

Figure 6a shows similar GPC curves for the neat PLA, the ultrasound processed unloaded PLA sample and that loaded with the maximum amount of TCS (i.e., $6 \mathrm{wt}$ \%). Basically, the maximum appeared at practically the same elution time (see dashed blue box) and differences can mainly be seen in the tail corresponding to higher elution times (i.e., fraction of low molecular weight chains) that slightly increased for the ultrasound processed samples (see dashed red box). Analyses indicated a slight decrease from an initial $M_{n}$ value of $43,000 \mathrm{~g} / \mathrm{mol}$ to $40,000-38,800 \mathrm{~g} / \mathrm{mol}$ after processing.
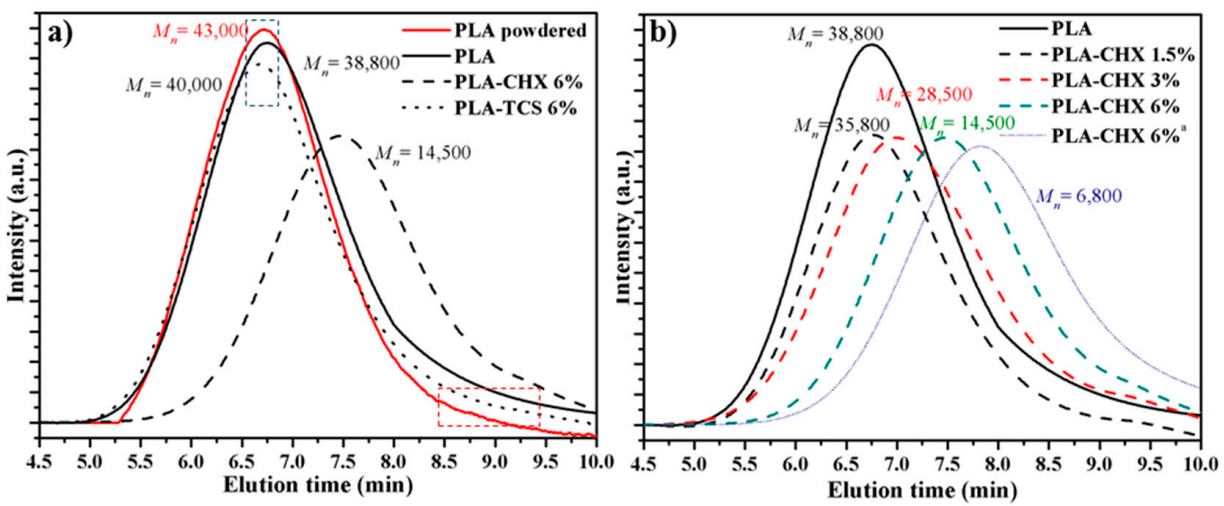

Figure 6. (a) Gel permeation chromatography (GPC) curves determined of initial powdered PLA, the molded PLA and its mixtures with the maximum assayed amounts of triclosan (TCS) and CHX; (b) comparison between GPC curves of processed PLA and PLA mixtures with the indicated percentages of CHX. For the sake of completeness, the curve corresponding to a molten PLA film loaded with $6 \mathrm{wt}-\%$ of $\mathrm{CHX}$ is also drawn (dotted curve). 
By contrast, incorporation of CHX caused a clear degradation at the percentage of $6 \mathrm{wt}-\%$ (Figure $6 \mathrm{~b}$ ) as evidenced by the decrease of $M_{n}$ from 43,000 g/mol to 14,500 g/mol. Furthermore, Figure $6 \mathrm{~b}$ demonstrated a correlation between the CHX load and the molecular weight decrease. Nevertheless, it is interesting to note that degradation becomes minimum for a load of $1.5 \mathrm{wt}-\%$ (i.e., $M_{n}$ decreased from $38,800 \mathrm{~g} / \mathrm{mol}$ to $35,800 \mathrm{~g} / \mathrm{mol}$, which means a loss less than $5 \%$ ). In order to verify if degradation was a direct consequence of the exposition to the ultrasonic source, we have also evaluated CHX loaded samples only submitted to the high temperature required to melt the PLA matrix. Figure $6 \mathrm{~b}$ shows the GPC curve of a PLA film loaded with $6 \mathrm{wt}-\%$ of CHX by solvent casting and then heated at a rate of $10{ }^{\circ} \mathrm{C} / \mathrm{min}$ to $180{ }^{\circ} \mathrm{C}$ (i.e., over the melting temperature of PLA). In this case, degradation was the highest since the molecular weight decreased up to $6600 \mathrm{~g} / \mathrm{mol}$. Thus, the presence of $\mathrm{CHX}$ molecules having a great proportion of amine groups (i.e., those belonging to the characteristic biguanide entities) accelerated the thermal degradation of PLA as was reported more explicitly in previous works [27-29]. Results pointed also out the great advantage of the new ultrasound technique. Probably, the low processing time (i.e., 1-2 s) that is in this case required allows for reducing significantly the degradation effect when the sample load is reduced (i.e., $1.5 \mathrm{wt}$-\%). By contrast, thermal degradation is evident when solvent casting films are heated up to the melting temperature since samples may remain at this high temperature for more than $3 \mathrm{~min}$.

Applications of microspecimens would need some mechanical requirements, such as elasticity or physical resistance. To this end, typical stress-strain measurements were performed to evaluate both the effect of processing and the incorporation of drugs. Representative plots are shown in Figure 7a and the corresponding mechanical parameters are summarized in Table 2. Figure $7 \mathrm{~b}$ shows the specific variation of the Young modulus and the deformation with the amount of loaded drug.
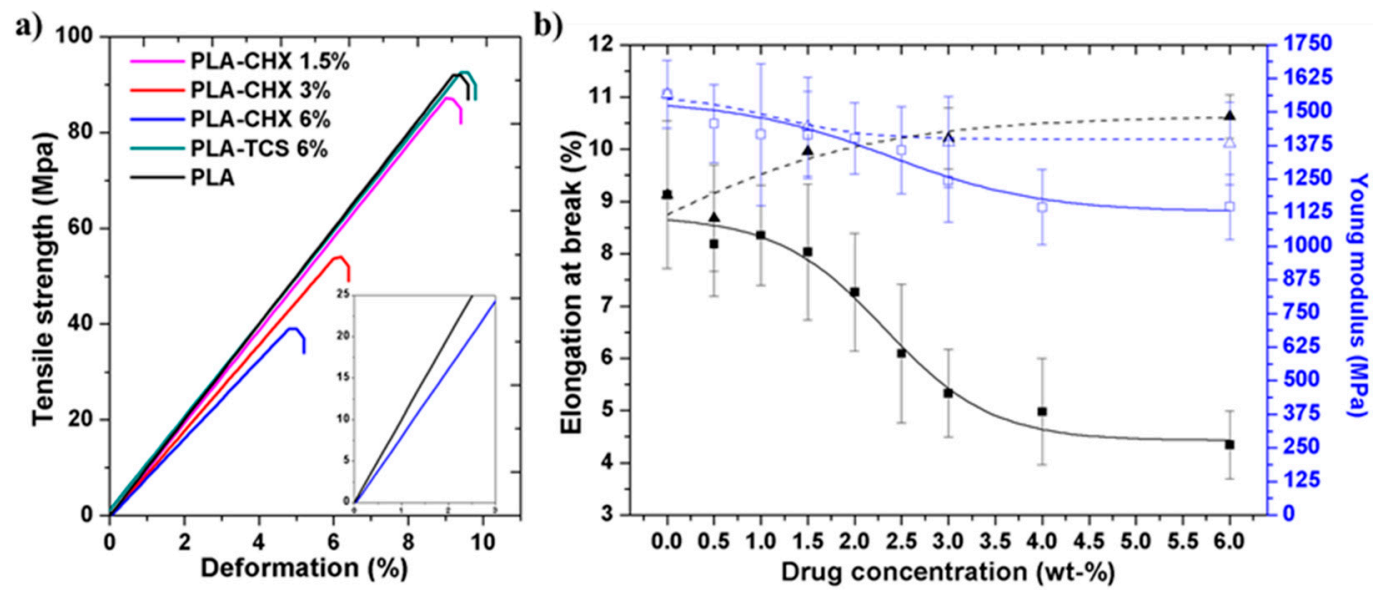

Figure 7. (a) stress-strain plots obtained from the representative indicated samples; (b) variation of the elongation at break (black curves) and the Young modulus (blue curves) with the TCS (dashed lines) or CHX (solid lines) load. All samples were processed under the optimized conditions of 24-300-1.2.

Samples loaded with chlorhexidine followed the same trend of the GPC assay. Thus, both properties clearly decreased for a load higher than $1.5 \mathrm{wt}-\%$ as a consequence of degradation. Moreover, when the load was $2.5 \mathrm{wt}-\%$, a sudden decrease was observed. Logically, the most sensitive property was the elongation at break, which decreased from an $8.5 \%$ to $4 \%$ for PLA-CHX $6 \mathrm{wt}-\%$. It should be indicated that high standard deviations were observed since this property is highly affected by the presence of minimum defects (e.g., fissures, cracks, etc) in the processed specimen. By contrast, the behavior of samples loaded with TCS is clearly different as expected from their minimum molecular degradation. Thus, Young modulus was practically constant for all TCS loaded specimens, while the elongation at break tended to increase (i.e., from $9 \%$ to $11 \%$ ) due to a plasticization effect of TCS. 
Table 2. Mechanical parameters extracted from stress-strain assays.

\begin{tabular}{ccccc}
\hline \multirow{2}{*}{ Drug \%-wt } & \multicolumn{2}{c}{ Chlorhexidine } & \multicolumn{2}{c}{ Triclosan } \\
\cline { 2 - 5 } & $\begin{array}{c}\text { Elongation at } \\
\text { Break (\%) }\end{array}$ & $\begin{array}{c}\text { Young Modulus } \\
\mathbf{( M P a )}\end{array}$ & $\begin{array}{c}\text { Elongation at } \\
\text { Break (\%) }\end{array}$ & $\begin{array}{c}\text { Young Modulus } \\
\text { (MPa) }\end{array}$ \\
\hline 0 & $9.13 \pm 1.4$ & $1565 \pm 127$ & $9.13 \pm 1.4$ & $1565 \pm 130$ \\
0.5 & $8.19 \pm 1.0$ & $1456 \pm 145$ & $9.11 \pm 1.0$ & $1558 \pm 120$ \\
1 & $8.35 \pm 0.9$ & $1416 \pm 264$ & $9.61 \pm 0.8$ & $1510 \pm 135$ \\
1.5 & $8.03 \pm 1.3$ & $1414 \pm 161$ & $9.95 \pm 0.5$ & $1445 \pm 190$ \\
2 & $7.26 \pm 1.1$ & $1401 \pm 132$ & $10.01 \pm 0.7$ & $1411 \pm 160$ \\
2.5 & $6.09 \pm 1.3$ & $1357 \pm 161$ & $10.19 \pm 0.8$ & $1393 \pm 110$ \\
3 & $5.33 \pm 0.8$ & $1243 \pm 152$ & $10.21 \pm 0.6$ & $1388 \pm 170$ \\
4 & $4.97 \pm 1.0$ & $1145 \pm 139$ & $10.50 \pm 0.4$ & $1380 \pm 140$ \\
6 & $4.34 \pm 0.7$ & $1146 \pm 120$ & $10.62 \pm 0.4$ & $1383 \pm 150$ \\
\hline
\end{tabular}

Micrographs shown in Figure 8 show the more irregular section surfaces of samples loaded with $\mathrm{CHX}$ as a consequence of some evidence of degradation. Note that, despite the major irregularities being caused by the blade cut, some imperfections can be seen in the chlorhexidine specimen (dashed circle). The observed erosion may also be induced by cavitation. Although this is not a goal of the present work, a correlation between cavitation events with damaged areas will provide useful information [30,31].
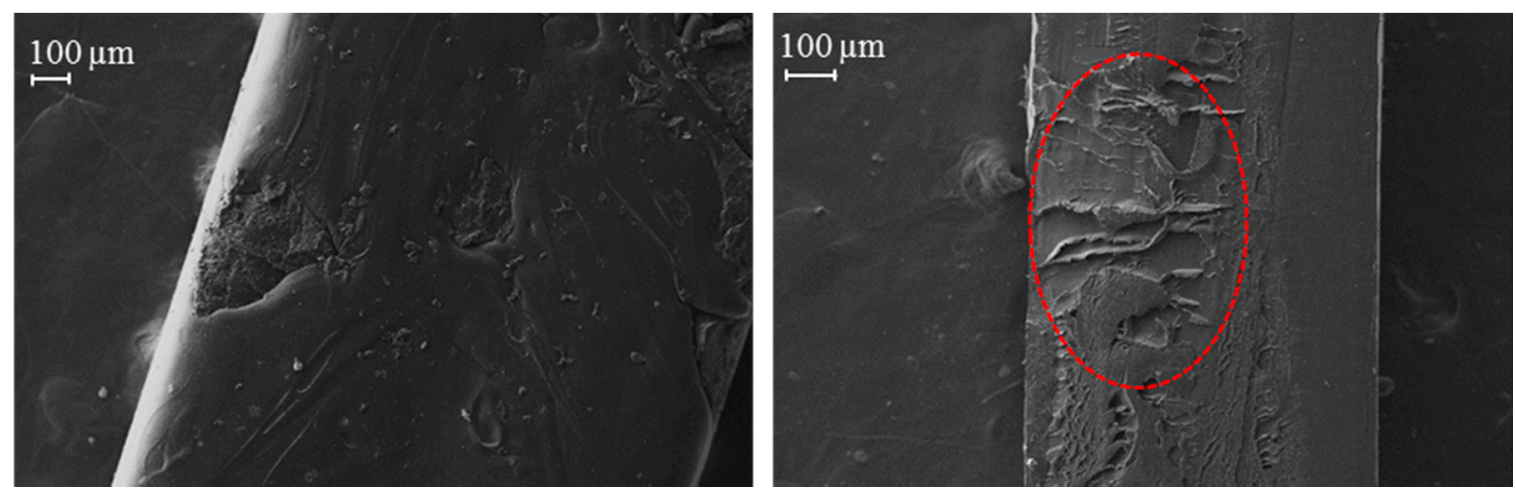

Figure 8. SEM micrographs of a PLA specimen loaded with $6 \mathrm{wt}-\%$ of TCS (left) and CHX (right) molded at 24-300-1.2 condition.

\subsection{Calorimetric Characterization}

DSC scans were performed in order to compare thermal properties of ultrasound micromolded pieces and melt crystallized samples, and also to study the influence of the loaded drug in the thermal properties. Figure 9 compares the DSC runs obtained directly from micromolded pieces (Figure 9a) and those registered from samples after being cooled $\left(10^{\circ} \mathrm{C} / \mathrm{min}\right)$ from the melt state (Figure $\left.9 \mathrm{~b}\right)$. The main characteristics are the following:

1. Specimens prepared by ultrasound micromolding showed relaxation endothermic overshoots over $T_{g}$, which indicated that the heating rate in DSC scan was higher than the previous cooling rate during glass formation. The observed peaks are complex but were minimized in the second heating run. It should be pointed out that relaxation peaks were not associated with a potential fusion of loaded drugs $\left(55^{\circ} \mathrm{C}\right.$ for TCS and $134^{\circ} \mathrm{C}$ for $\mathrm{CHX}$ ) since they were also detected for unloaded PLA.

2. All samples showed exothermic cold crystallization peaks, which were higher for the micromolded specimens as a consequence of their higher amorphous content. The associated enthalpy clearly increased also when drugs were loaded and even were split into two peaks for loads around $6 \mathrm{wt}-\%$. 
3. The melting process was similar for all PLA samples and those loaded with $3 \mathrm{wt}-\%$ of CHX. This fusion was characterized by a complex melting peak with a shoulder at $164{ }^{\circ} \mathrm{C}$ and a main peak at $170{ }^{\circ} \mathrm{C}$ as it is well described. The melting enthalpy was also comparable, indicating that a similar degree of crystallinity was achieved after cold crystallization. Nevertheless, the second heating run of the sample loaded with $6 \mathrm{wt}-\%$ of $\mathrm{CHX}$ showed a melting peak with a clearly lower enthalpy (i.e., $21.65 \mathrm{~J} / \mathrm{g}$ with respect to $38.09 \mathrm{~J} / \mathrm{g}$ measured for the melt crystallized PLA sample), lower melting peak temperature $\left(157^{\circ} \mathrm{C}\right.$ with respect to $\left.168-170{ }^{\circ} \mathrm{C}\right)$ and a higher temperature for the cold crystallization peak (i.e., $125^{\circ} \mathrm{C}$ with respect to $114-118^{\circ} \mathrm{C}$ ). The different behavior of such sample is in agreement with the above-mentioned degradation process that should be maximum at the end of the second heating run due to the considerable exposure to high temperatures (i.e., during the performed heating and cooling runs) and also demonstrates the clear loss of properties.
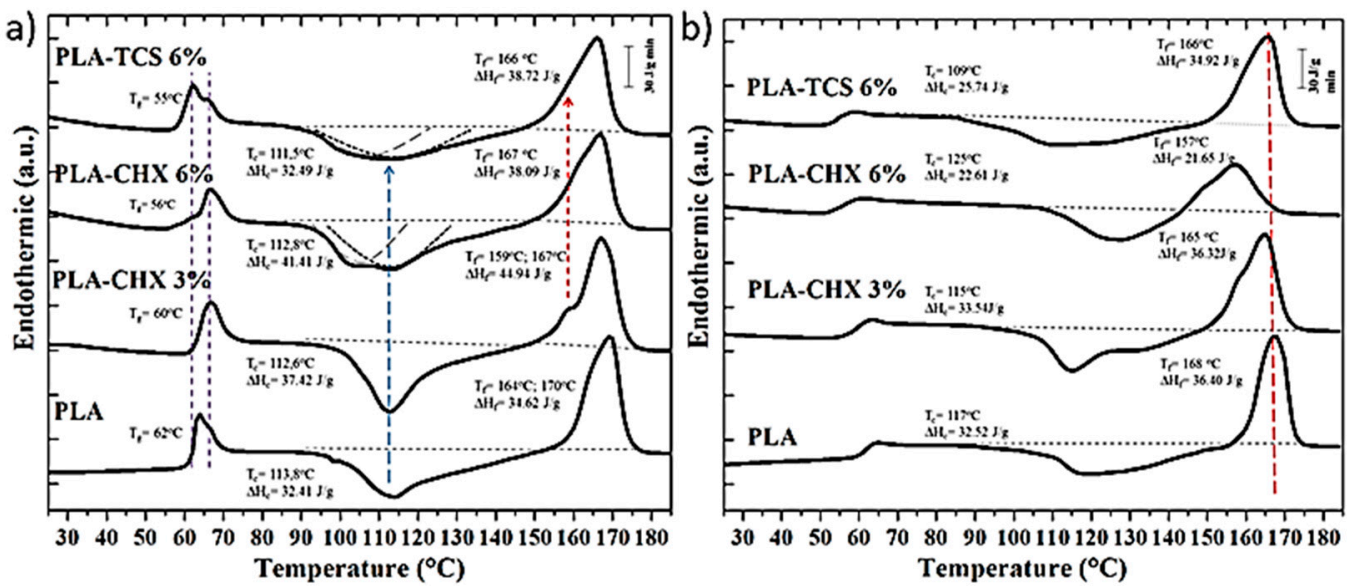

Figure 9. Differential scanning calorimetric curves corresponding to the first heating (a) and second heating (b) runs of neat PLA, PLA loaded with $3 \%$ and $6 \%$ of CHX and PLA loaded with $6 \%$ of TCS. Both heating runs were performed at $10^{\circ} \mathrm{C} / \mathrm{min}$.

Thermogravimetric analyses were also carried out to see the influence of the loaded drugs on the thermal stability of processed samples. Figure 10 shows the typical TGA and DTGA curves of PLA with a main decomposition step at $370{ }^{\circ} \mathrm{C}$, a small shoulder at lower temperature and an onset degradation temperature of $345^{\circ} \mathrm{C}$. Both TCS and CHX loaded samples gave rise to a reduction of the onset temperature to around $200{ }^{\circ} \mathrm{C}$, which means that cautions should be taken to avoid the exposure to such high temperature. Fortunately, this onset temperature is clearly higher than the PLA melting temperature in such a way that TCS processed samples did not show any evidence of degradation. Similar TGA and DTGA curves were detected for CHX loaded curves, but degradation cannot be discarded as made evident by the previous analyses. It seems that molecular scission took place without rendering small volatile fragments that could be detected in the TGA profiles. Degradation rate was also different between neat PLA and drug loaded samples since peak temperature slightly increased for TCS and CHX loaded specimens. Minimum differences were also found in the char yield, which was higher for $\mathrm{CHX}$ loaded samples probably as a consequence of its higher aromatic content. 


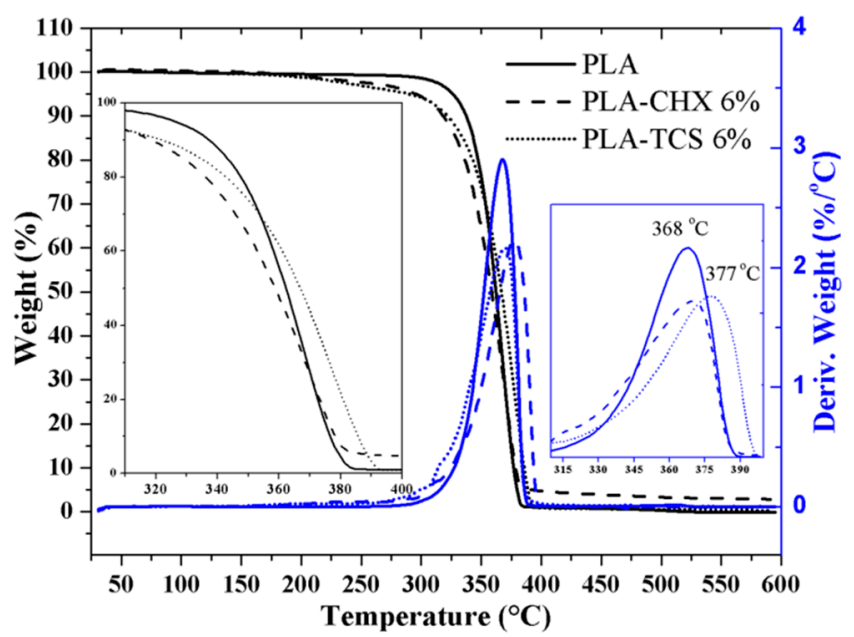

Figure 10. Thermogravimetric and differential thermogravimetric profiles of ultrasound processed specimens of PLA and PLA loaded with $6 \mathrm{wt}$ - $\%$ of each drug. Magnification of onset temperature region and DTGA peaks are shown in the insets.

\subsection{Drug Load and Release}

The study of the drug loading process was done considering two points: the amount of drug loaded in the specimen and its homogeneity (i.e., the drug can be distributed in a non-homogeneous way along the flow direction). Note also that some amount of drug should rest in the sprue and consequently the drug effectively incorporated in the specimen is different to the amount of drug loaded in the processing chamber. Therefore, results will be always referred to as the percentage of drug in each evaluated specimen. In order to determine the uniformity of the drug distribution, the specimen was cut in three parts along the flow direction as shown in Figure 11a. The percentage of drug incorporated in each section was determined by UV measurements of three replicas. Comparison between the average values determined for each one of the three parts allowed for getting an idea about the homogeneity of the sample.

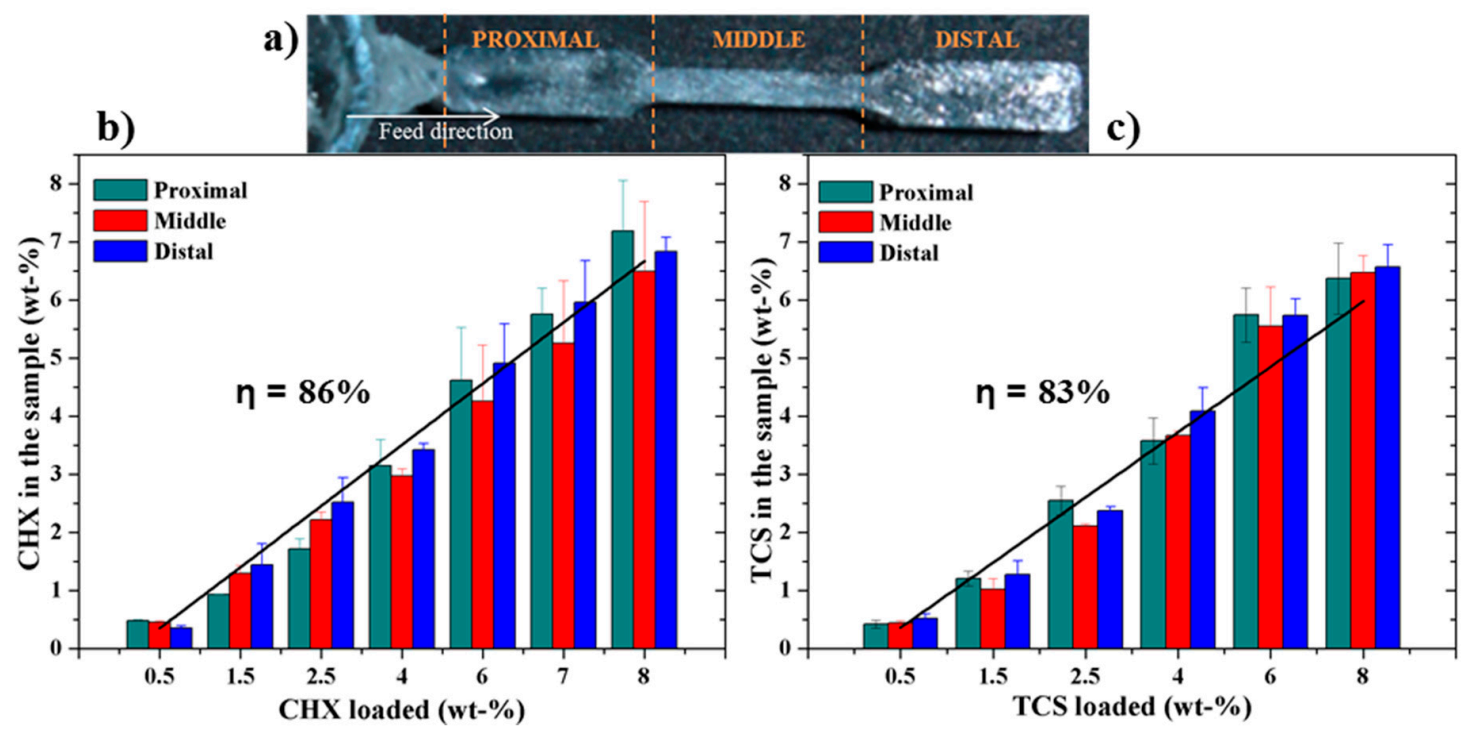

Figure 11. Schematic representation of the three selected sections for each specimen (a). Percentage of loaded CHX (b) and TCS (c) drugs for the three specimen sections with respect to the percentage introduced in the processing chamber. 
Figure $11 b, c$ compare the theoretical percentage that should be loaded and the real percentage incorporated in each analyzed section. The loading efficiency was around $83-86 \%$ for both drugs, independently of the total load. A relatively good distribution along the flow direction was found, although the proximal region (i.e., that closest to the sprue) tended to have a slightly higher percentage. Results attained with CHX and TCS were similar despite the great differences in molecular size and even in their hydrophobic character.

Release studies were performed in static conditions, which are obviously different to the continuous renewal of the medium that occurs in the human body. The performed study tries to use media with different polarity (i.e., by controlling the PBS:ethanol ratio) in order to evaluate drug retention and compare kinetic data. Specifically, the release assays were carried out in two types of media: ethanol and a PBS-ethanol mixture with $70 \%$ of PBS. Ethanol was selected in order to favor the drug release due to its capability to swell the PLA matrix. The second medium kept a certain content of ethanol and had a similar hydrophobicity of a typical serum medium as has previously been reported $[32,33]$.

The release profiles of both drugs in the PBS-ethanol medium are shown in Figure 12 (dashed lines). These releases follow a first order kinetic without a significant burst effect. The release rate was slow and specifically $155 \mathrm{~h}$ were required for a delivery of $50 \%$. This release was faster for the more hydrophilic CHX drug (i.e., $k_{1}$ values of $0.0356 \mathrm{~h}^{-1}$ and $0.027 \mathrm{~h}^{-1}$ for CHX and TCS, respectively). The specimens were clearly too wide and compact to get a complete release in the limited exposure time of $155 \mathrm{~h}$.

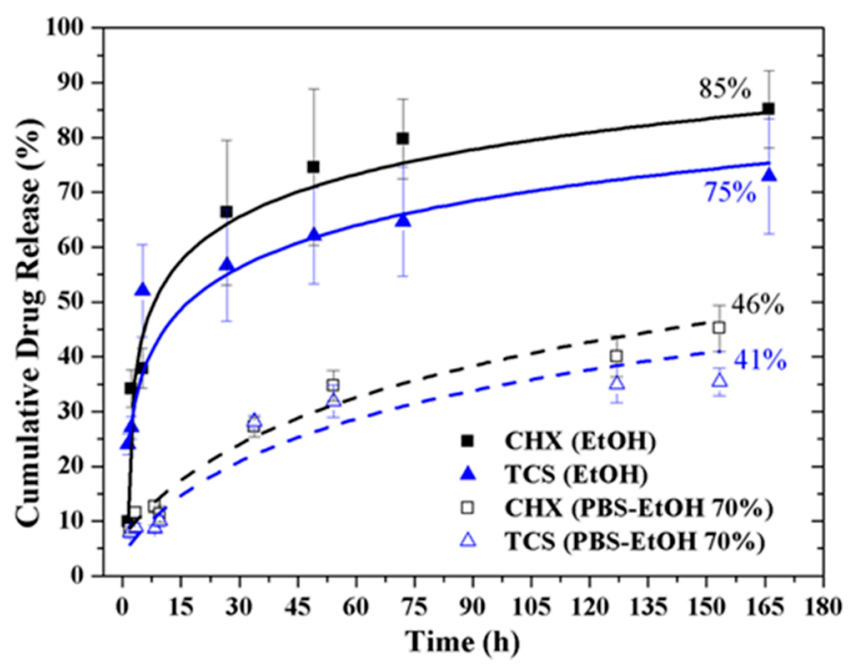

Figure 12. Release profile of PLA samples loaded with 3 wt-\% of TCS (blue) and CHX (black) in absolute ethanol (solid lines) and PBS-EtOH 70\% (dashed lines).

Ethanol media increased the release rate and allowed the release of drugs located in the inner part. Specifically, release percentages of $85 \%$ and $75 \%$ were achieved after $165 \mathrm{~h}$. This release was characterized by a clear burst effect (40-45\% after only $8 \mathrm{~h}$ of exposure) of drugs located near the outer layer of microspecimens followed by a first order kinetic process with values of the same magnitude order of those found in the PBS containing medium (i.e., $0.0367 \mathrm{~h}^{-1}$ and $0.0297 \mathrm{~h}^{-1}$ for CHX and TCS, respectively).

\subsection{Antibacterial Properties of CHX and TCS Loaded Micromolded Pieces}

The results of agar tests for representative Gram-negative (E. coli) and Gram-positive (S. epidermidis) bacteria are shown in Figure 13. The presence of an inhibition halo in the loaded samples, not observed around the neat PLA, reflects the drug antibacterial activity. Therefore, the ultrasound heating source does not have a negative effect in the antibacterial activity of the evaluated drugs. These results show that the drugs maintain their molecular structure intact and consequently their activity during 
the micromolding process. The sizes of the inhibition halo are directly linked with antibacterial activity level. Accordingly, the activity of both drugs against S. epidermidis was much higher than for E. coli. Comparing the CHX and TCS response, a greater effect was observed for TCS loaded samples despite its smaller release rate, its greater inherent bactericide activity demonstrated as discussed below. Differences in the size of the inhibition halo were nevertheless minimized when high drug concentrations were used. The previously indicated small release rate, which is derived from the high specimen compaction, suggests that the initial bactericide effect was caused by the drug located at the specimen surface, which needs a minimum loading concentration to be significant.

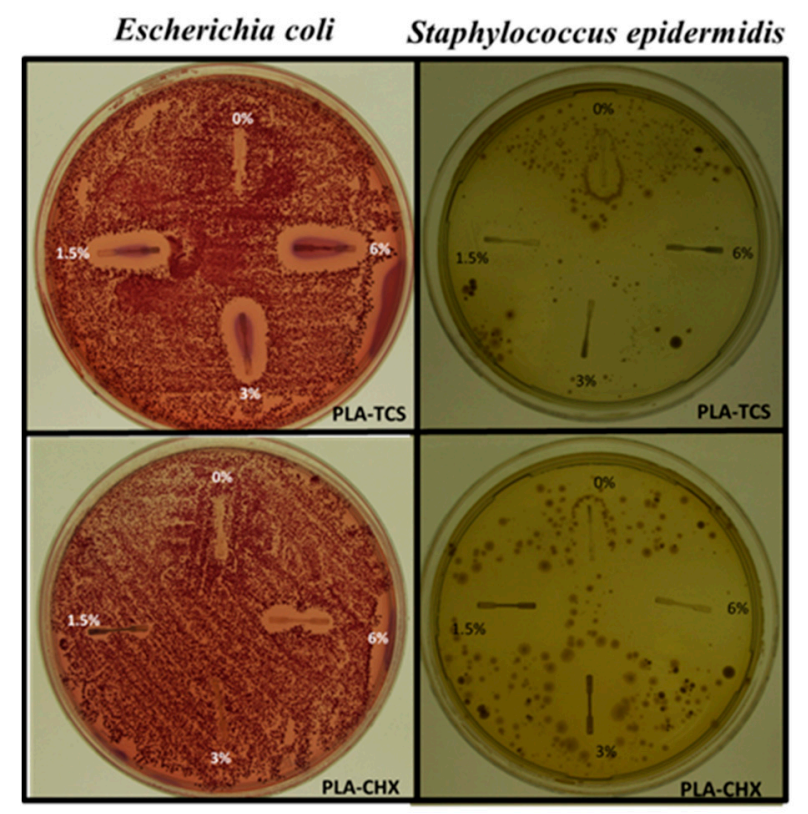

Figure 13. Agar tests performed with PLA samples loaded with $1.5 / 3 / 6 \mathrm{wt}-\%$ of each drug (TCS or CHX) for E. coli and S. epidermidis. For the sake of completeness, PLA unloaded samples are also evaluated.

These results shown in Figure 13 can be explained taking into account the different antibacterial mechanisms of both drugs. TCS diffuses through the bacterial cytoplasmic membrane and interferes with its lipid metabolism, leading to clear inhibition halos for both bacteria. By contrast, CHX salts are dissociated at physiologic $\mathrm{pH}$ and consequently positively charged $\mathrm{CHX}$ cations become the delivered agents. The bactericidal effect of CHX is a result of the binding of this cationic molecule with the negatively charged bacterial cell walls. Responses are consequently dependent on the structure of the bacterial walls, which are only constituted by peptidoglycans (PGs) in the case of Gram-positive bacteria, while these PGs are coated by proteins, phospholipids and lipopolysaccharides in Gram-negative bacteria. Coatings provide a protective effect to the action of CHX cationic molecules. Therefore, halos produced by TCS (large-medium sizes) and CHX (reduced size) can be well-differentiated in an E. coli medium.

Both TCS and CHX act as biocides at high concentrations and at lower concentrations have a bacteriostatic effect. Drug effects can be analyzed through the broth culture quantification assay. Figure 14 compares the bacterial growth curves of unloaded (solid lines) and loaded (dashed and dotted lines for CHX and TCS, respectively) PLA processed specimens. Both drugs had a clear bactericidal and bacteriostatic effect in the two studied bacterium media. Thus, bacterial growth was reduced to close to $20 \%$, related to the $100 \%$ of neat PLA. PLA loaded with $3 \mathrm{wt}-\%$ of CHX firstly had a high bactericidal effect, suppressing the bacterial growth up to $24 \mathrm{~h}$, and, subsequently, a bacteriostatic activity that kept the total bacterial growth under $20 \%$. For the samples loaded with TCS, the bactericidal effect was a little less effective since a delay of the growth around 10-15 $\mathrm{h}$ was observed with respect to CHX. Nevertheless, the bacteriostatic effect was active for the whole assay, allowing 
for reaching similar growth levels in both bacterium media than those observed for CHX loaded specimens. These results are very interesting because they firstly show that loaded micromolded pieces provide enough bactericidal concentration in the medium, and secondly that drugs are released in a continuous way to guarantee clear bacteriostatic effects. In summary, the studied micromolded pieces loaded with TCS or CHX remain efficiently protected against eventual bacterial infections over time.
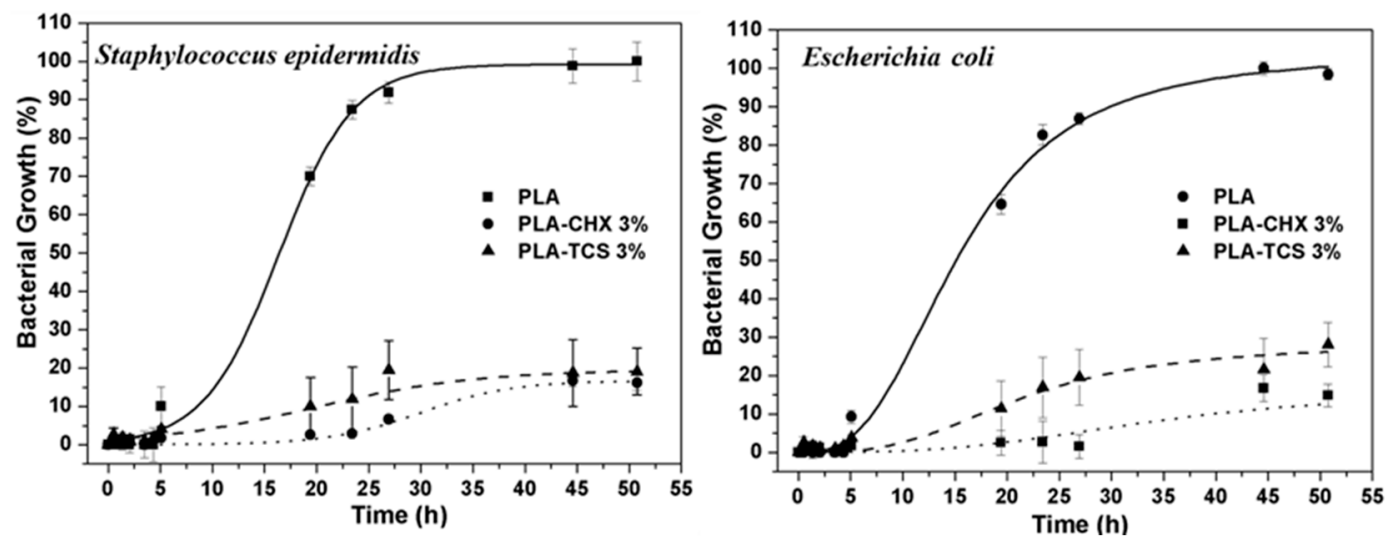

Figure 14. Staphylococcus epidermidis (left) and Escherichia coli (right) bacterial growth in presence of PLA samples and PLA loaded with $3 \mathrm{wt}-\%$ of TCS or CHX.

\section{Conclusions}

Micromolded specimens loaded with bactericide agents could be effectively processed using ultrasound as an effective energy source. Results supported the potential of this new processing technology for producing micropieces from biodegradable and biocompatible polymers such as polylactide, and pharmacological drugs. Specimens with minimum degradation and a uniform drug distribution could be easily obtained. More interestingly, the low processing time required for the ultrasound technology appears highly advantageous when compounds that enhance thermal degradation should be incorporated into the polymer matrix. In this sense, the decrease in the final degradation of pieces loaded with $\mathrm{CHX}$ is notable with respect to specimens obtained by classical melt processing. CHX and TCS loaded microspecimens retained the activity of TCS and CHX after ultrasound processing. Specifically, drugs were slowly released from the micropieces with a rate that was slightly dependent on their hydrophilicity. The release in a PBS-ethanol medium (70\% of PBS) followed a first order kinetics with constants of $0.0356 \mathrm{~h}^{-1}$ and $0.027 \mathrm{~h}^{-1}$ for CHX and TCS, respectively. Bactericide and bacteriostatic effects against both Gram-positive and Gram-negative bacteria were detected for the two drugs at the beginning and at the final step of exposure to the bacterium media, respectively. Bacterial growth could be reduced to close to $20 \%$ when micropieces were loaded with only $3 \mathrm{wt}-\%$ of any of the selected CHX and TCS drugs.

Author Contributions: C.O. performed experiments; L.F. was involved in thermal characterization studies; L.J.d.V. performed biological assays; and J.P. supervised project direction.

Funding: The authors are in debt to support from MINECO and FEDER (RTI2018-101827-B-I00) and the Generalitat de Catalunya (2017SGR373).

Conflicts of Interest: The authors declare no conflict of interest.

\section{References}

1. Attia, U.M.; Marson, S.; Alcock, J.R. Micro-injection moulding of polymer microfluidic devices. Microfluid. Nanofluid. 2009, 7, 1. [CrossRef]

2. Lee, C.-Y.; Wu, G.-W.; Hsieh, W.-J. Fabrication of micro sensors on a flexible substrate. Sens. Actuators A Phys. 2008, 147, 173-176. [CrossRef] 
3. Besten, C.D.; Hal, R.E.G.V.; Munoz, J.; Bergveld, P. Polymer bonding of micro-machined silicon structures. In Proceedings of the IEEE Micro Electro Mechanical Systems, Travemunde, Germany, 4-7 February 1992; pp. 104-109.

4. Heckele, M.; Bacher, W.; Müller, K.D. Hot embossing-The molding technique for plastic microstructures. Microsyst. Technol. 1998, 4, 122-124. [CrossRef]

5. Heckele, M.; Schomburg, W.K. Review on micro molding of thermoplastic polymers. J. Micromech. Microeng. 2004, 14, R1. [CrossRef]

6. Michaeli, W.; Spennermann, A.; Gärtner, R. New plastification concepts for micro injection moulding. Microsyst. Technol. 2002, 8, 55-57. [CrossRef]

7. Sacristán, M.; Puiggalli, J.; Planta, X.; Morell, M. Effects of ultrasonic vibration on the micro-molding processing of polylactide. Ultrason. Sonochem. 2014, 21, 376-386. [CrossRef] [PubMed]

8. Truckenmuller, R.; Ahrens, R.; Chenga, Y.; Fischer, G.; Saile, V. An ultrasonic welding based process for building up a new class of inert fluidic microsensors and -actuators from polymers. Sens. Actuators A 2006, 132, 385-392. [CrossRef]

9. Chen, J.; Chen, Y.; Li, H.; Lai, S.-Y.; Jow, J. Physical and chemical effects of ultrasound vibration on polymer melt in extrusion. Ultrason. Sonochem. 2010, 17, 66-71. [CrossRef]

10. Michaeli, W.; Opferman, D. Ultrasonic plasticising for micro injection moulding. In 4M 2006-Second International Conference on Multi-Material Micro Manufacture; Elsevier: Oxford, UK, 2006; pp. 345-348.

11. Michaeli, W.; Kamps, T.; Hopmann, C. Manufacturing of polymer micro parts by ultrasonic plasticization and direct injection. Microsyst. Technol. 2011, 17, 243-249. [CrossRef]

12. Chen, G.; Guo, S.; Li, H. Ultrasonic improvement of rheological behavior of polystyrene. J. Appl. Polym. Sci. 2002, 84, 2451-2460. [CrossRef]

13. Auras, R.; Lim, L.-T.; Selke, S.E.M.; Tsuji, H. Poly(lactic acid): Synthesis, Structures, Properties, Processing, and Applications; Wiley: Hoboken, NJ, USA, 2010.

14. Williams, D.F. Biocompatibility of Clinical Implant Materials; CRC Press: Boca Raton, FL, USA, 1981.

15. Ikada, S.S.Y. Medical Applications. In Poly(lactic acid): Synthesis, Structures, Properties, Processing, and Applications; Auras, R., Lim, L.-T., Selke, S.E.M., Tsuji, H., Eds.; Wiley: Hoboken, NJ, USA, 2010; Chapter 27.

16. Conn, J.; Oyasu, R.; Welsh, M.; Beal, J.M. Vicryl (polyglactin 910) synthetic absorbable sutures. Am. J. Surg. 1974, 128, 19-23. [CrossRef]

17. Burger, C.; Kabir, K.; Rangger, C.; Mueller, M.; Minor, T.; Tolba, R.H. Polylactide (LTS) causes less inflammation response than polydioxanone (PDS): A meniscus repair model in sheep. Arch. Orthop. Trauma Surg. 2006, 126, 695-705. [CrossRef] [PubMed]

18. Armentano, I.; Bitinis, N.; Fortunati, E.; Mattioli, S.; Rescignano, N.; Verdejo, R.; Lopez-Manchado, M.A.; Kenny, J.M. Multifunctional nanostructured PLA materials for packaging and tissue engineering. Prog. Polym. Sci. 2013, 38, 1720-1747. [CrossRef]

19. Shah Mohammadi, M.; Bureau, M.N.; Nazhat, S.N. 11-Polylactic acid (PLA) biomedical foams for tissue engineering. In Biomedical Foams for Tissue Engineering Applications; Netti, P.A., Ed.; Woodhead Publishing: Cambridge, UK, 2014; pp. 313-334.

20. Lopes, M.S.; Jardini, A.L.; Filho, R.M. Poly (Lactic Acid) Production for Tissue Engineering Applications. Procedia Eng. 2012, 42, 1402-1413. [CrossRef]

21. Tyler, B.; Gullotti, D.; Mangraviti, A.; Utsuki, T.; Brem, H. Polylactic acid (PLA) controlled delivery carriers for biomedical applications. Adv. Drug Deliv. Rev. 2016, 107, 163-175. [CrossRef] [PubMed]

22. Lassalle, V.; Ferreira, M.L. PLA Nano- and microparticles for drug delivery: An overview of the methods of preparation. Macromol. Biosci. 2007, 7, 767-783. [CrossRef] [PubMed]

23. Kellomäki, M.; Törmälä, P. Ultrasonic moulding of bioabsorbable polymers and polymer/drug composites. J. Mater. Sci. Lett. 1997, 16, 1786-1789. [CrossRef]

24. Allen, T.M.; Cullis, P.R. Drug delivery systems: Entering the mainstream. Science 2004, 303, 1818-1822. [CrossRef]

25. Nyborg, W.L. Acoustic streaming near a boundary. J. Acoust. Soc. Am. 1958, 30, 329-339. [CrossRef]

26. Koruk, H.; El Ghamrawy, A.; Poulipoulos, A.N.; Choi, J.J. Acoustic particle palpation for measuring tissue elasticity. Appl. Phys. Lett. 2015, 107, 223701. [CrossRef] 
27. Planellas, M.; Sacristán, M.; Rey, L.; Olmo, C.; Aymamí, J.; Casas, M.T.; del Valle, L.J.; Franco, L.; Puiggalí, J. Micro-molding with ultrasonic vibration energy: New method to disperse nanoclays in polymer matrices. Ultrason. Sonochem. 2014, 21, 1557-1569. [CrossRef] [PubMed]

28. Li, S.; Girod-Holland, S.; Vert, M. Hydrolytic degradation of poly(D,L-lactic acid) in the presence of caffeine base. J. Control. Release 1996, 40, 41-53. [CrossRef]

29. Alexis, F. Factors affecting the degradation and drug-release mechanism of poly(lactic acid) and poly[(lactic acid)-co-(glycolic acid)]. Polym. Int. 2005, 54, 36-46. [CrossRef]

30. Haworth, K.J.; Bader, K.B.; Rich, K.T.; Holland, C.K.; Douglas Mast, T. Quantitative Frequency-Domain Passive Cavitation Imaging. IEEE Trans. Ultrason. Ferroelectr. Freq. Control 2017, 64, 177-191. [CrossRef] [PubMed]

31. Pouliopoulos, A.N.; Li, C. Rapid short-pulse sequences enhance the spatiotemporal uniformity of acoustically driven microbubble activity during flow conditions. J. Acoust. Soc. Am. 2016, 140, 2469-2480. [CrossRef] [PubMed]

32. Márquez, Y.; Cabral, T.; Lorenzetti, A.; Franco, L.; Turon, P.; del Valle, L.J.; Puiggalí, J. Incorporation of biguanide compounds into poly(GL)-b-poly(GL-co-TMC-co-CL)-b-poly(GL) monofilament surgical sutures. Mater. Sci. Eng. C 2017, 71, 629-640. [CrossRef] [PubMed]

33. Zurita, R.; Puiggalí, J.; Rodríguez-Galán, A. Triclosan release from coated polyglycolide threads. Macromol. Biosci. 2006, 6, 58-69. [CrossRef]

(C) 2019 by the authors. Licensee MDPI, Basel, Switzerland. This article is an open access article distributed under the terms and conditions of the Creative Commons Attribution (CC BY) license (http://creativecommons.org/licenses/by/4.0/). 